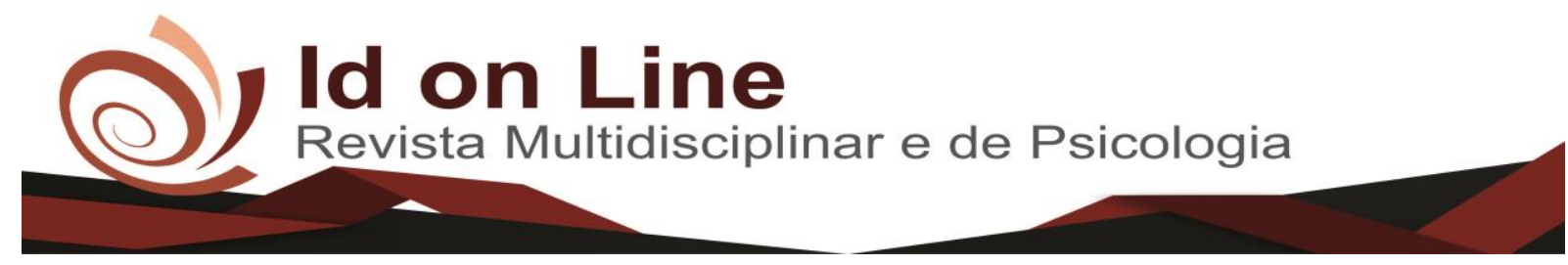

DOI: 10.14295/idonline.v14i52.2751

Comment

\title{
Educação Inclusiva e o Papel do Professor
}

\author{
Jaíne da Silva Brito ${ }^{1}$; Verônica Rejane Lima Teixeira ${ }^{2}$
}

\begin{abstract}
Resumo: O presente artigo teve como objetivo focar nas necessidades da educação inclusiva com o propósito de analisar as leis que favorecem os direitos das pessoas que possui qualquer tipo de deficiência, a participarem do ensino regular como observa o artigo 28 da LBI, no qual no passado não tinha essa circunstância, pois as pessoas que tinham alguma imperfeição, eram excluídas da sociedade por serem consideradas como incapazes e débeis. Atualmente há leis que defendem o direito dessas pessoas no ensino regular, no qual se tem a capacidade de se desenvolver em meio a outros que não tenham deficiência alguma, e sobretudo é estimulado a prática de respeito as diferenças tratando assim a inclusão entre todos. Além de serem introduzidas no ensino regular, esses alunos são acompanhados pelo atendimento especializado com um profissional bem qualificado para o acompanhamento do desenvolvimento dessas pessoas. Para que isso ocorra de forma satisfatória tanto para o aluno, como para esse profissional, é preciso que as instituições públicas possam possibilitar formações continuadas para que esses profissionais se sintam seguros ao trabalhar com esse público alvo, podendo assim aplicar práticas de ensino que tenham resultados positivos no desenvolvimento de cada aluno pois cada ser tem seu tempo de aprender tanto pessoas com deficiência como pessoas que não possuem qualquer deficiência porque o meio intelectual de um ser para outro é bastante variável. Está pesquisa bibliográfica ressaltou assuntos importantes, dos quais foram necessários e vantajosos para a instrução sobre a educação inclusiva e a relevância do papel do professor.
\end{abstract}

Palavras-Chave: Inclusão, Professor, Formação.

\section{Inclusive Education and the Role of the Teacher}

\begin{abstract}
This article aimed to focus on the needs of inclusive education with the purpose of analyzing the laws that favor the rights of people who have any type of disability, to participate in regular education as provided for in article 28 of the LBI, in which the past did not have this circumstance, because people who had some imperfection were excluded from society because they were considered as incapable and weak. Currently, there are laws that defend the right of these people in regular education, in which they have the ability to develop among others who have no disabilities, and above all, the practice of respecting differences is encouraged, thus treating inclusion among all. In addition to being introduced to regular education, these students are accompanied by specialized service with a well qualified professional to monitor the development of these people. For this to occur satisfactorily for both the student and this professional, it is necessary that public institutions can enable continuous training so that these professionals feel safe when working with this target audience, thus being able to apply teaching practices that have results positive in the development of each student because each being has time to learn both people with disabilities and people who do not have any disability because the intellectual environment from one being to another is quite variable. This bibliographic research highlighted important issues, which were necessary and advantageous for the instruction on inclusive education and the relevance of the teacher's role.
\end{abstract}

Keywords: Inclusion, Teacher, Training.

\footnotetext{
${ }^{1}$ Faculdade de Ciências Humanas do Sertão Central (FACHUSC). jainebrito462@ gmail.com;

${ }^{2}$ Faculdade de Ciências Humanas do Sertão Central (FACHUSC). veronica.teixeira@ fachusc.com.
} 


\section{Introdução}

A convocação da pessoa com deficiência no âmbito escolar é uma discussão de várias reflexões e propostas diferenciadas, pelas particularidades inerentes a pessoa humana e pelas discrepantes barreiras viventes no contexto escolar, portanto, é um desafio da escola compreender e articular políticas públicas de inclusão da criança autista no âmbito educacional garantindo uma meditação da convenção pedagógica voltada para diversidade.

O sistema de educação no Brasil passou por várias mudanças no decorrer dos tempos, e o ensino escolar de alunos com deficiência e transtornos globais do desenvolvimento e altas habilidades/superdotação existe como grande desafio os espaços escolares, erguerem novos métodos de ensino. Neste contesto qual o papel do professor na educação inclusiva? Quais práticas pedagógicas podem ser utilizadas pelos professores? Como incluir com compromisso e responsabilidades esses alunos com deficiência no sistema de ensino?

A formação continuada do professor fortifica as práticas inclusivas na escola como fortalecedor do processo de aprendizagem, o atendimento especializado necessita de profissionais formados e orientados para prestar esse atendimento, observando as especificidades do aluno com autismo.

Para o educador exige-se uma prática contextuada e flexibilizada, levando em conta ainda a escuta, eo acolhimento dos diversos conceitos dos atos dos sujeitos para fortalecer a formação educacional da criança autista. De acordo com Baptista (2002) ressalta que:

\footnotetext{
Pontos necessários para uma educação efetivamente inclusiva: processo educativo desenvolvido a partir da existência de dificuldades favorecendo a pesquisa e a recriação da prática pedagógica, a importância dada à ação e à centralidade do sujeito, a flexibilidade da estrutura metodológica, a participação de todos na elaboração das regras.
}

A presente pesquisa foi realizada no intuito de esclarecer sobre o dever do professor para alunos com deficiência e transtornos globais do desenvolvimento e altas habilidades/superdotação. E a pontar as melhores formas de adequar o ensino aos mesmos. Também, tentar trazer algumas dicas de como obter mais conhecimento para aprender lidar com esse público.

Esses profissionais de ensino muitas vezes se encontram desnorteados ao se deparar com alunos cujos esses tenham necessidades especiais, talvez pela falta de preparação com relação a formação, e também por não ter tido experiência em trabalhar com a inclusão na educação. 
Por meio dessa pesquisa bibliográfica foi estudado teóricos que particularmente falavam sobre a importância do ensinar e da formação dos professores, dos quais deixaram bem esclarecida a importância do professor bem preparado para atuar na educação inclusiva.

A escola inclusiva tem um papel fundamental de estabelecer a inclusão dessas pessoas com necessidades especiais em sala de aula para que também tenham a oportunidade de se expressar em meio a outros, e poder ganhar autonomia própria dentro de si. Com a chegada da inclusão a escola tem o papel de se adaptar a esse meio, e se aprimorar para trabalhar com a mesma. Assim como o profissional da educação é um fator importante para estabelecer a inclusão entre seus alunos. É proposto que haja um espaço na formação do professor voltada para a educação inclusiva onde tais terão a oportunidade de trabalhar com esse novo, de forma gratificante e aproveitadora onde saberá agir em diferentes situações e ao mesmo momento saberá como aplicar os conhecimentos necessários aos seus alunos para que haja o processo de aprendizagem .

\section{Fundamentação Teórica}

\section{Educação Especial E Educação Inclusiva}

A Educação especial no Brasil, iniciou nos tempos do império, teve início a partir das instituições, (Instituto dos Meninos Cegos, em 1854), e o (Instituto dos Surdos Mudos em 1857), os mesmos estão situados no Rio de Janeiro. No começo do século XX, as escolas especiais começaram a serem espalhadas por toda a Europa e Estados Unidos. A educação especial nasceu com o processo de ensino para crianças com deficiência intelectual criado pela a medica italiana Maria Montessori, início do século XX, esse método teve uma grande repercussão mundial e até nos tempos de hoje é muito utilizado, no Brasil foi tão aceito que é usado na educação pré-escolar de crianças sem deficiência.

A secretaria de Educação Especial do MEC (SESP), considera a educação especial como:

[...] um processo que visa a promover o desenvolvimento das potencialidades de pessoas portadoras de deficiências, condutas típicas ou altas habilidades, e que abrange os diferentes níveis e graus do sistema de ensino. Fundamenta-se em referenciais teóricos e práticos compatíveis com as necessidades específicas de seu alunado. O processo deve ser integral, fluindo desde a estimulação essencial até os graus superiores de ensino. Sob esse enfoque sistêmico, a educação especial integra o 
sistema educacional vigente, identificando-se com sua finalidade, que é a de formar cidadãos conscientes e participativos (BRASIL, MEC/SEESP,1994, p.17).

Nesses termos pode-se considerar que a educação especial é dotada de vários direitos e o mais essencial deles é a garantia desses alunos dentro das escolas para que tenham a oportunidade de se desenvolverem melhor na companhia de profissionais qualificados e possam mostrar o seu potencial, e que cada ser tem a capacidade de evoluir em algo quando se tem a oportunidade de demostrar o que se sente, como forma de se expressar.

Diferente da educação inclusiva a educação especial necessita de um espaço e materiais pedagógicos específicos para o tipo de necessidade do aluno, com tudo isso toda atenção do professor é voltada aquele aluno e o atendimento se torna totalmente especializado.

De acordo com a Lei de diretrizes e Bases da Educação Nacional (LDB), no artigo 58:

Entende-se por educação especial, para os efeitos desta Lei, a modalidade de
educação escolar oferecida preferencialmente na rede regular de ensino, para
educandos com deficiência, transtornos globais do desenvolvimento e altas
habilidades ou superdotação. (Redação dada pela Lei no ${ }^{\circ} 12.796$, de 2013)

Já a LBD diz que essa modalidade de ensino é oferecida na rede regular como sendo preferencial com o intuito desses educandos terem a oportunidade de desenvolverem suas habilidades numa sala de aula do ensino regular ao lado de alunos que não possuem deficiência ou seja no ambiente normal de sala de aula. O principal objetivo é incluir pessoas com necessidades especiais no mesmo ambiente das outras pessoas. É abrir o espaço para todas as crianças sem divisórias e inserir as mesmas regras e funções a todos sem exceções.

As crianças e jovens portadoras de alguma deficiência também podem contar com o auxílio do Atendimento Educacional Especializado (AEE), onde o profissional especializado tem parceria com o professor da sala, para juntos analisarem as principais dificuldades de seus alunos e encontrar ambientes e formas estratégicas de ensino para cada estudante. $\mathrm{O}$ desenvolvimento da aprendizagem do aluno deve ser avaliada pela a sua progressão ou regressão nas suas atividades, sendo assim deixando claro que esse atendimento acontece em outro momento e não dentro da aula normal, mas é de suma importância essa parceria entre educador da sala de aula e o profissional de atendimento especializado, para ter bons resultados de aprendizagem do aluno. 
Educação inclusiva é quando uma diversidade de alunos, mesmo diante de suas diferenças convivem na mesma sala de aula. É quando todos se respeitam e são tratados da mesma forma e o mesmo saber é aplicado a todos.

Em outros tempos, a história da inclusão foi almejada com grande rejeição, preconceito e discriminação. Relata-se na literatura da Roma Antiga que crianças nascidas com deficiência na era cristã, foram afogados por serem apontados como defeituosas e débeis. Na Grécia Antiga, Platão descreve na sua obra "A República" o fato das crianças com má formação física ou com deficiência serem sacrificadas ou ocultadas pelo poder público.

Nos dias de hoje a inclusão é tratada de forma especial onde todos tem o direito de ser tratados da mesma forma, onde a deficiência não seja levada em conta, mas a capacidade do interagir e de conviver no mesmo espaço com pessoas diferentes. Na escola essa inclusão é atribuída principalmente na sala de aula, onde os alunos convivem com portadores de deficiências, mas se tem o mesmo tratamento entre todos os alunos, para que não exista a falta de respeito, e indiferença entre os mesmos. Mantoan (1997), ressalta que a inclusão trouxe a mudança no ambiente escolar, o qual teve que se adaptar aos meios dessa nova realidade, também citou que os professores a partir desse novo, tiveram que buscar atualização de suas práticas para trabalhar com esse público.

[...] a inclusão é um motivo para que a escola se modernize e os professores aperfeiçoem suas práticas e, assim sendo, a inclusão escolar de pessoas deficientes torna-se uma consequência natural de todo um esforço de atualização e de reestruturação das condições atuais do ensino básico (MANTOAN,1997, P.120).

Por si só, a inclusão é um meio de romper os paradigmas educacionais, que ficaram registradas no passado, onde a pessoa com deficiência não tinha a oportunidade de visitar a sala de aula regular, e onde não se tinha o intuito de acreditar nas evoluções e capacidades dessas pessoas. Atualmente é visto que as crianças que tem alguma deficiência podem desenvolver as mesmas habilidades das outras crianças. E são vistas como guerreiras por conseguirem superar as dificuldades e progredirem na evolução no dia a dia, pois para que haja essa progressão essas crianças precisão de todo apoio, escolar, de seus profissionais e tanto das escolas como de seus profissionais e também do total apoio da família a qual tem o principal papel de acompanhar todo o procedimento de seu filho para que ele possa ter bons resultados. Pois essa educação deve oferecer espaços que entrelacem o saber e a inclusão de todos. 


\title{
O Sistema de Ensino e o Processo de Inclusão
}

A legislação federal de 1988 no artigo 205 descreve a educação, um direito de todos, garantindo o desenvolvimento da pessoa, o exercício da cidadania e a qualificação para o trabalho. Por fim, relata que é dever do Estado ofertar o atendimento educacional especializado (AEE), na rede regular de ensino. O artigo 28 da (LBI) diz o seguinte:

\begin{abstract}
Incumbe ao poder público assegurar, criar, desenvolver, implementar, incentivar, acompanhar e avaliar: I - sistema educacional inclusivo em todos os níveis e modalidades, bem como o aprendizado ao longo de toda a vida; II - aprimoramento dos sistemas educacionais, visando a garantir condições de acesso, permanência, participação e aprendizagem, por meio da oferta de serviços e de recursos de acessibilidade que eliminem as barreiras e promovam a inclusão plena; (ARTIGO 28, da LBI e incisos I e II.).
\end{abstract}

Nesse caso a lei deixa bem claro que é um direito de todos participarem da escola e que essa rede de ensino possa se adequar ao recebimento de seus alunos com deficiência e prestar a eles o atendimento especializado na rede de ensino regular. $\mathrm{O}$ sistema de ensino tem o dever de matricular todos os alunos levando a escola a se adaptar as necessidades do educando assegurando condições para boas aprendizagens.

A escola deve ser um ambiente acolhedor para as crianças e não um ambiente de exclusão ou discriminatório, pois todos somos diferentes independente de ter deficiência ou não, somos sujeitos diversificados com culturas, raças, gêneros e pensamentos diferentes. Por tanto a um equilíbrio entre essas diferenças tornando-as passivas que é o respeito mútuo. O respeito deve ser inserido nas escolas para que todos se sintam abraçados e seguros no mesmo ambiente.

Há escolas que se quer, realizam matriculas de crianças com necessidades especiais alegando que as mesmas não possuem a estrutura para o acolhimento daquele educando, ou relata que na escola não possui um profissional adequado para o atendimento, assim é identificado ainda a falta de preparação de escolas em mau investimento na estrutura escolar para acolher esse público, e na formação de seus educadores para o recebimento destes alunos.

A escola inclusiva se tem como papel de não apenas matricular seus alunos, mas de oferecer condições necessárias para a sua atuação também de garantir a permanência deles e a boa qualidade de ensino. Assim a (ONU), 1994 diz que uma escola para todos é aquela que celebra as diferenças e se projeta atendendo às necessidades de cada ser. 
O princípio da inclusão consiste no reconhecimento da necessidade de se caminhar rumo à "escola para todos"- um lugar que inclua todos os alunos celebre a diferença, e a aprendizagem e responda as necessidades individuais. (ONU, 1994, P. 5)

Assim fica bem claro o verdadeiro papel da escola com relação a inclusão, onde todos devem respeitar suas diferenças e tenham o devido apoio assistencial e adaptacional para assim ter a garantia de um bom desenvolvimento na escola.

\section{Práticas Pedagógicas Inclusivas na Educação}

Para ponto de partida dessa prática pedagógica, primeiramente o educador deve conhecer o seu aluno, saber o que ele mais gosta, o que lhe faz sentir mais seguro, seus medos e dificuldades. É essencial que o professor tenha conhecimento desses fatores, pois é a partir deles que poderá desenvolver atividades dentro do padrão de cada aluno. Para o acontecimento desse processo é necessário que o professor conheça o (PDI), Plano de Desenvolvimento Individual.

Quando as particularidades dos alunos não são levados em consideração pelo educador, fica muito difícil aplicar atividades estratégicas com resultados positivos, pois cada aluno tem seu tempo de aprender tanto com deficiência como sem. Pois a evolução varia de pessoa para pessoa. Todos têm capacidade de aprender sejam suas dificuldades; intelectuais, sensoriais ou físicas. O processo de cada pessoa é singular então não deve ser distinguido da mesma forma.

$\mathrm{Na}$ educação inclusiva o planejamento das aulas deve ser constantemente planejados e cooperativos, onde se deve atender as necessidades de seus alunos. Tendo como guia os conteúdos curriculares. É de fundamental importância que dentro desse planejamento esteja incluído também os jogos e brincadeiras, pois para a criança é muito importante esse contato com os outros, a partir de momentos alegres e atrativos através de jogos lúdicos e brincadeiras das quais além de gerar um bem estar entre essas crianças também gera aprendizagem. Para Oliveira (2000, p. 17),

\footnotetext{
Aprender a agir, inclusive a brincar, só se dá em contato íntimo e significativo com o outro que, via de regra, no início da vida, é a mãe ou quem a substitua. Não há possibilidade de aprendizagem e consequentemente de humanização fora do convívio social e, mais do que isso, sem vivenciar e sentir realmente um vínculo afetivo, estável e confiável, que no começo é muito mais sentido do que manifesto. A dimensão socializadora do brincar. (OLIVEIRA, 2000, p. 17).
} 
O professor regente pode estar fazendo esse planejamento com ajuda de outras pessoas como os familiares, profissional da sala de (AEE) e ate mesmo com alunos como participantes do processo de aprendizagem. $\mathrm{O}$ atendimento educacional especializado contribui muito no planejamento pedagógico inclusivo, pois esse especialista saberá desenvolver atividades diversificadas que beneficiam os estudantes com deficiências, e (TEA) transtorno do espectro autista, e altas habilidades/super dotação. O profissional pode se planejar tanto na educação especial como na inclusiva, pois as mesmas habilidades, trabalhadas com esse público pode ser aplicado com outras crianças.

O planejamento é algo muito importante para se tratar, pois ele deve ser sempre atualizado e estrategicamente modificado a partir das respostas de interação e avanços do aluno, sem fugir dos parâmetros curriculares. A medida que o aluno vai respondendo bem em meio ao desenvolvimento daquele planejamento significa que aquela forma de ensino está dando certo e o professor deve continuar com seu planejamento, mas sempre atualizando para que o aluno continue dando bons resultados. Mas se o mesmo não tenha adquirido bons resultados, o profissional terá que estruturar seu planejamento de outra maneira até obter bons resultados de aprendizagem, isso pode ser feito também com crianças que não possuem deficiência para que tenham um ensino de qualidade e de bons resultados.

\section{Formação Continuada de Professor na Perspectiva Inclusiva}

A formação continuada na perspectiva inclusiva, é muito mais do que uma capacitação. Ela é constituída como de extrema importância para a prática pedagógica inclusiva. Seu interesse é de adquirir reflexão e buscar novos saberes, analisar o cotidiano escolar e buscar através dessas formações estratégias e movimentos para mudar o que não estar dando certo na sala de aula. Assim as autoras Isaia e Bolzan, 2011, ressaltam a importância da formação;

\footnotetext{
Processo que se orienta para a constante apropriação de conhecimentos/saberes/fazeres próprios á área de atuação de cada profissão, para os quais as ideias de conhecimento pedagógico compartilhado e redes de interações são imprescindíveis, implica também na sensibilidade do docente como pessoa e profissional em termos de atitudes e valores, tendo a reflexão como componente, de desenhar sua própria trajetória. A professoralidade instaura-se ao longo de um percurso que engloba de forma integrada de trajetória e de formação, consubstanciada no que costumamos denominar de trajetórias formativas. (ISAIA; BOLZAN, 2011, P. 187, grifo das autoras).
} 
Isso é de fundamental importância, para que haja essas formações com pessoas especializadas e que saibam passar para o educador a firmeza de se trabalhar com a inclusão. É muito importante que os gestores da rede pública e também escolar, ofereçam estas formações continuadas para que o professor esteja confiante em lidar com uma sala, cuja tenha crianças ou adolescentes com deficiência, pois o grande medo nos dias de hoje é justamente a falta de preparação desses profissionais para lidar com o público alvo.

A mal formação e a insegurança desses educadores ao se tratar de educação inclusiva é muito grande, pois se sentem despreparados por não ter tido o contato com esse público alvo durante sua graduação, pois a formação inicial não é suficiente para trabalhar com o meio inclusivo. E quando se deparam na sala não sabem o que fazer. Por esse e outros motivos o educador necessita de um acompanhamento por meios de formações, pois elas são essenciais para que essas crianças e jovens tenham um melhor desenvolvimento.

O professor bem preparado, saberá lidar com as mais diversas situações sem sair de seu foco de mediador do conhecimento. A escola como o todo tem essa necessidade de aprender lidar com o processo de inclusão cujo todos terão o convívio com esse público por isso seria interessante além da formação especializada com o professor da sala, os diretores escolares oferecerem na própria escola pequenas formações com seus funcionários, para que toda a escola possa acolher melhor esse público.

\section{Metodologia}

A presente pesquisa foi realizada de forma qualitativa, onde foi usado a ferramenta do Google Acadêmico e por meio desse foi pesquisado vários artigos dentro do assunto exposto. A pesquisa foi realizada também por meio de revistas eletrônicas das quais tratavam do assunto abordado, e por meio de livros cujo autores foram citados dentro do texto. A presente pesquisa é bibliográfica e o conteúdo pesquisado foi muito proveitoso. Pois foi obtido muitas informações com relação ao tema, esses foram redigidos de forma clara para que o leitor possa ter uma boa compreensão do assunto explanado e exposto durante todo o artigo.

\section{Resultados e Discussão}

No início do presente trabalho foram apontadas indagações, as quais teriam o objetivo de 
serem respondidas ou pelo menos esclarecidas. Durante a pesquisa bibliográfica foi abordado vários assuntos pertinentes ao tema, dos quais tiveram grandes contribuições para com o estimado assunto.

Falar da educação inclusiva e o papel do professor é estimativamente importante pois a educação inclusiva ainda sofre com a falta de adaptações escolares e pela não preparação de educadores, apesar deste público ter por lei o direito de participar da rede regular de ensino com o auxílio do atendimento especializado, existem instituições de ensino que simplesmente não tem capacidade de receber esses alunos justamente pela falta de estrutura e por não terem profissionais especializados para lidar com os mesmos. Por esse motivo é essencial que seja chamado a atenção dos governadores públicos que invistam mais, na qualificação dos professores, principalmente nas formações continuas de educação inclusiva, para que esses profissionais tenham segurança dentro da sala de aula ao passar o conhecimento para seus alunos, e adequar o espaço escolar para a acessibilidade das crianças e jovens com deficiência. Assim respondendo a primeira questão, o papel do professor na educação inclusiva é de ser, facilitador no processo de aprendizagem e contribuir na evolução de seus alunos através do planejamento contínuo e o respeito mútuo entre eles.

As práticas pedagógicas que podem ser utilizadas pelos professores são basicamente associadas a estratégias no planejamento do professor a partir do momento que o mesmo tenha um certo conhecimento sobre o seu aluno. Pois como foi relatado no presente artigo cada aluno possui um tempo estimado de aprender e o professor deve respeitar esse fator. So assim conhecendo as particularidades de seus alunos ele pode acompanhar a progressão das atividades aplicadas.

O artigo 28, da LBI, deixa bem claro nos incisos I e II que o poder público deve assegurar, criar o desenvolvimento, implementação, incentivo, acompanhamento e a avaliação do sistema educacional inclusivo, como o aprendizado desses alunos com deficiência, tendo como garantia condições de acesso, permanência, participação e aprendizagem. Assim partido dessas garantias da LBI, esses alunos são incluídos no sistema de ensino com compromisso e responsabilidade.

Nesse sentido finalizo aqui a discussão no ato de ter encontrando as respostas das indagações iniciais, as quais me deixam bastante satisfeita com as resoluções encontradas a partir de uma prolongada pesquisa. 


\section{Considerações Finais}

Concluindo as indagações do início do artigo. Todas foram respondidas de forma positiva, demonstrando ser o processo da educação inclusiva, nas escolas, um importante elemento influenciador nas formações continuas do profissional da educação inclusiva. Também demonstrou-se a importância das leis da LBI, PDI e LDB, essenciais para a efetivação dos direitos das pessoas com deficiência, as quais impulsionaram um olhar especial para a inclusão das pessoas com deficiência no ambiente educacional.

\section{Referências}

BAPTISTA, C. R. Integração e autismo: Análise de um percurso integrado. In C. R. Baptista, \& C. A. Bosa, (Eds.), Autismo e educação: Reflexões e propostas de intervenção (pp. 127-139). Porto Alegre: Artmed, 2002.

BRASIL. Lei no 12.796, de 4 de Abril de 2013. Altera a Lei no 9.394, de 20 de dezembro de 1996, que estabelece as diretrizes e bases da educação nacional, para dispor sobre a formação dos profissionais da educação e dar outras providências. Disponível em: http://www.planalto.gov.br/ccivil_03/_ato2011-2014/2013/lei/112796.htm. Acesso em: 12.08.2020.

BRASIL. Ministério da Educação. Secretaria de Educação Especial. Política Nacional de Educação Especial. Brasília: MEC/SEESP, 1994.

ISAIA. S.M.A, e BOLZAN, A.M.R.M. Tessituras Formativas: articulação entre movimentos da docência e da aprendizagem docente. in: Qualidade da educação superior: a universidade como lugar de formação [recurso eletrônico] / organizadora, Silvia Maria de Aguiar Isaia; colaboradoras, Dores Pires Vargas Bolzan, Adriana Moreira da Rocha Maciel. -Dados eletrônicos. -Porto Alegre: EDIPUCRS, 2011.

MANTOAN, Maria Teresa Eglér. A Integração de pessoas com deficiência: contribuições para uma reflexão sobre o tema. São Paulo: Memnon. Editora SENAC, 1997.

OLIVEIRA, Vera Barros de (org). O brincar e a criança do nascimento aos seis anos. Petrópolis, RJ: Vozes, 2000.

\section{Como citar este artigo (Formato ABNT):}

BRITO, Jaíne da Silva; TEIXEIRA, Verônica Rejane Lima. Educação Inclusiva e o Papel do Professor. Id on Line Rev.Mult.Psic., Outubro/2020, vol.14, n.52, p. 718-728. ISSN: 1981-1179.

Recebido: 21/10/2020; Aceito: 23/10/2020. 